\title{
A compact miniature fractal planar antenna for RFID readers
}

\author{
Mohamed Ihamji ${ }^{1}$, Elhassane Abdelmounim², Jamal Zbitou ${ }^{3}$, Hamid Bennis ${ }^{4}$, Mohamed Latrach $^{5}$ \\ ${ }^{1,2}$ LASTI Laboratory, FST of Settat, Hassan 1st University, Morocco \\ ${ }^{3}$ LMEET Laboratory, FST of Settat, Hassan 1st University, Morocco \\ ${ }^{4}$ TIM Research Team, EST of Meknes, Moulay Ismail University, Morocco \\ ${ }^{5}$ Microwave Group, ESEO, France
}

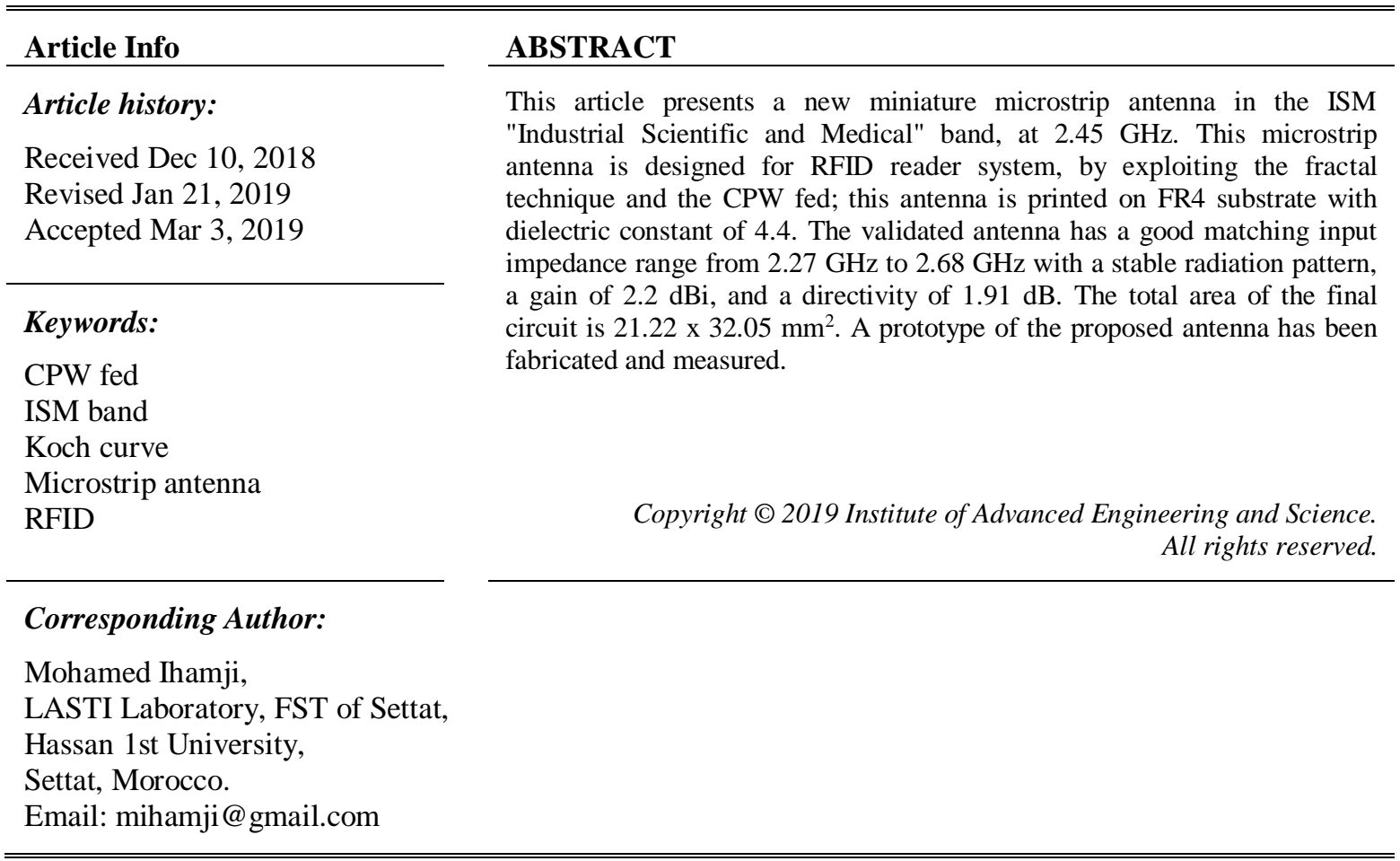

\section{INTRODUCTION}

RFID (Radio Frequency Identification) system contains generally a reader, and one or more transponders or tags [1-5]. The microstrip antennas are the most used in wireless communication, because they are low weight, low profile, mechanically robust, ease of fabrication and conformable to planar and non-planar surfaces. They are composed of three parts which are radiating element, substrate and ground, and have many structure forms such as rectangular, elliptic, circular and triangular, etc [6-8]. RFID antennas operate usually in either the low frequency region $(30-300 \mathrm{kHz})$, the high frequency band (3-30 MHz), the ultra-high-frequency band $(300 \mathrm{MHz}-1 \mathrm{GHz})$, or in the microwave band $(1 \mathrm{GHz}-40 \mathrm{GHz})$.

The RFID system is used in many applications where fitting into smaller areas is required as logistics management, transport, health, and access control. This demand of small RFID devices sizes leads to develop new RFID antennas with small size and light weight structures [9]

Many techniques are used to design a miniature antenna, as the slot technique [10-13], the fractal structure, the Defected Ground Structure (DGS) [14], or the use of metamaterial structure [15]. One of the techniques used to design easily a miniature antenna is the use of the fractal structures. The fractal technique is used to generate radiating structure by repeating a fine element in arbitrary or regular scales. Two types of fractal objects exist: deterministic and random. Deterministic are generated from several scaled-and rotated copies of themselves using a recursive algorithm. Random fractals also contain elements of randomness that allow simulation of natural phenomena. However, the proposed fractal antennas have been mostly designed with a deterministic fractal technique. Many popular fractal geometries are referred in the literature, as the Koch fractal, the Sierpinski fractal, the Hilbert fractal, the Minkowski and the Square Curve fractals. 
The antennas with Koch fractal geometry are commonly used in virtue of their attractive properties: they have small size, multi-frequency performance, and better radiation pattern in high frequency [16-26].

They are many methods to feed the microstrip antennas, as the microstrip line, the slot line or the CPW (Coplanar Wave Guide) line. The advantage of CPW fed antenna is their wide bandwidth compared to other feds which is approved by many research [27].

In this paper, a new miniature low cost microstrip antenna is proposed at frequency of $2.45 \mathrm{GHz}$, this antenna is designed by using the fractal structure and the CPW fed. It was initially designed and simulated by using CST-MW Studio, then fabricated to confirm the simulation results.

\section{RESEARCH METHOD}

The proposed antenna is composed of a rectangular radiating patch; this antenna is fed by 50 ohms Coplanar Wave Guide line. It is achieved by using an FR4 substrate with Dielectric constant $\varepsilon r=4.4$, Loss tangent $\tan \delta=0.025$, Thickness $\mathrm{H}=1.60 \mathrm{~mm}$, Metal thickness $\mathrm{t}=0.035 \mathrm{~mm}$. The non radiating edges of the microstrip antenna are designed with the Koch curve. The size reduction of this antenna is obtained by the space filling property of fractal geometries.

Figure 1 shows the 3 iterations of the Koch curve, the geometry of the first iteration (iteration 1) is composed of seven copies $(n=7)$ of the basic geometry (iteration 0$)$, and the segments lengths of the first iteration are reduced by a factor of $4(\mathrm{~h}=4)$. So, The reduction reached with 2 iterations of width patch is equal to $(\mathrm{n} / \mathrm{h})^{2}=(7 / 4)^{2}=3.06$.

The patch antenna is designed with fractal side, and has the length $\mathrm{L}$ and the width $\mathrm{W}$, which are optimized to get the correct resonant frequency. It is connected to a Coplanar Wave Guide line with the width Wf and the length Lf. Figure 2 illustrates the face of the prposed antenna. The dimensions of the proposed antenna are presented in the following Table 1.

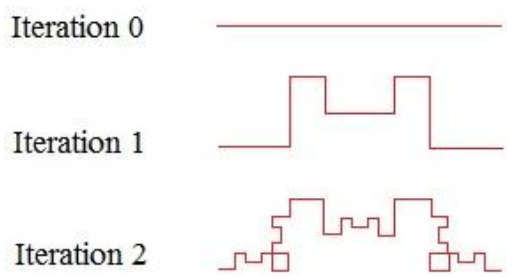

Figure 1. The 3 iterations of the koch curve

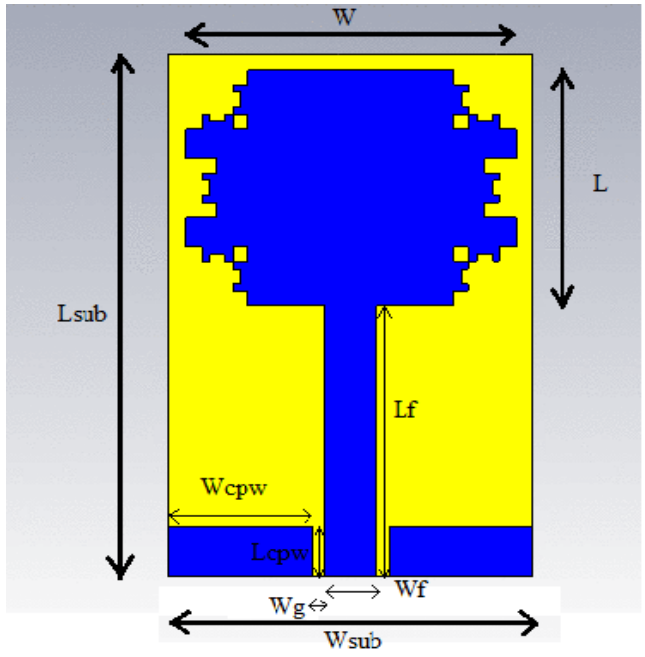

Figure 2. Geometry of the proposed antenna: top face

Table 1. Antenna Dimensions

\begin{tabular}{cc}
\hline Antenna Dimensions & Optimized Value $(\mathrm{mm})$ \\
\hline $\mathrm{L}$ & 14.45 \\
$\mathrm{~W}$ & 19.225 \\
Lsub & 32.05 \\
Wsub & 21.225 \\
Lf & 16.6 \\
Wf & 3 \\
Wg & 0.75 \\
\hline
\end{tabular}

\section{RESULTS AND DISCUSSION}

A miniaturized antenna with fractal side and Coplanar Wave Guide fed is proposed. The width and length value of this antenna are optimized on CST EM solver. 


\subsection{Simulated Results}

The antenna has good matching input impedance in the ISM band, as shown in Figure 3, this good matching could ensure a longer antenna reading distance. The return loss (S11) obtained is equal to -35.87 $\mathrm{dB}$ with this patch antenna. The bandwidth value is equal approximately to $327 \mathrm{MHz}$.

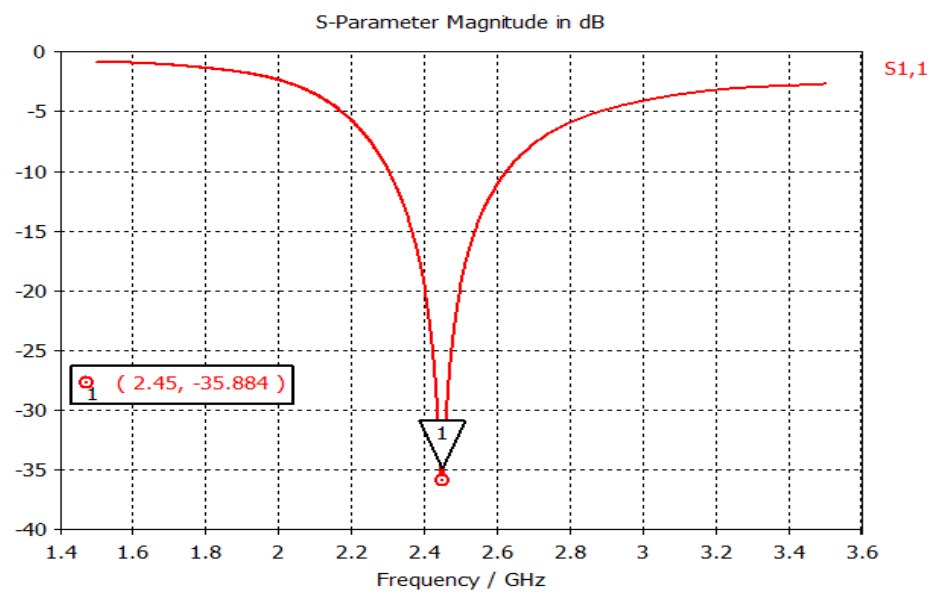

Figure 3. Return loss (S11) value of the proposed antenna

The gain and directivity are equal respectively to $2.2 \mathrm{dBi}$ and $1.91 \mathrm{~dB}$. Figure 4 and Figure 5 illustrate the 2D radiation patterns in E-plane and H-plane respectively; the proposed antenna has an omnidirectional radiation pattern for $\mathrm{H}$-plane and bi-directional radiation pattern for E-plane, which is important to detect easily others Tags by this antenna Reader.

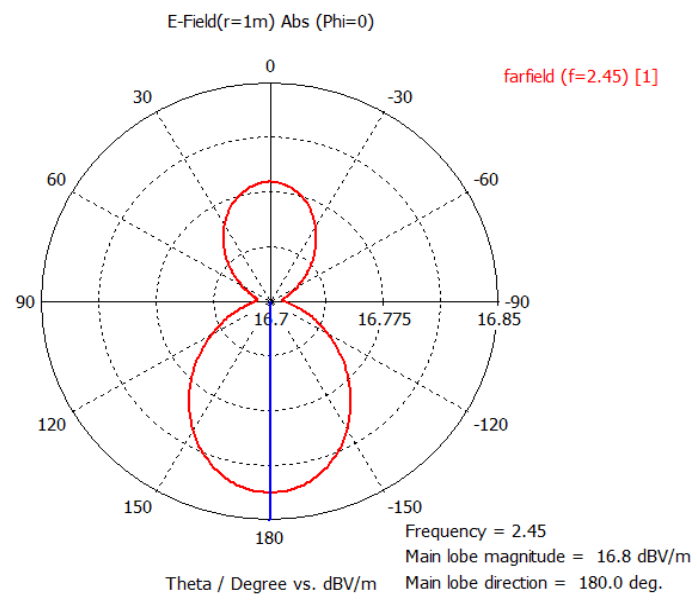

Figure 4. 2D radiation patterns of the proposed antenna in E-plane

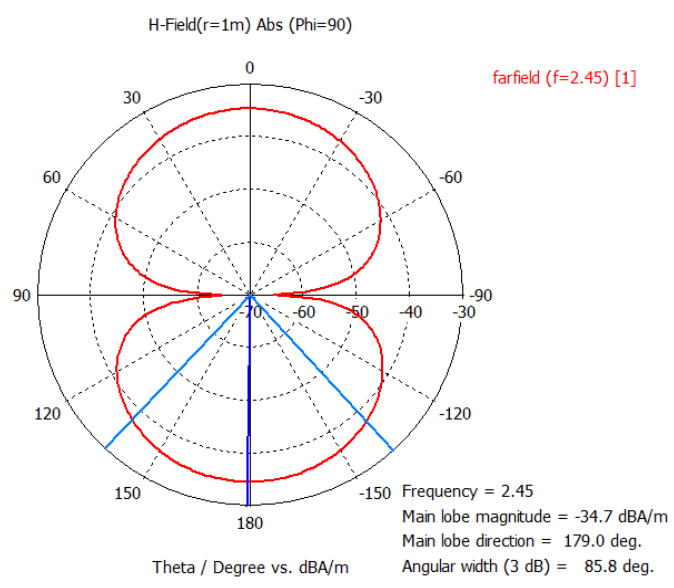

Figure 5. 2D radiation patterns of the proposed antenna in H-plane

Figure 6 shows the surface current distribution of the proposed antenna at $2.45 \mathrm{GHz}$. A maximum current is observed around the fractal side, and around the feed line. The results obtained of the proposed antenna, summarized in Table 2, show a good return loss S11, and a good bandwidth for RFID applications. The gain and directivity value are acceptable. The CPW-feed has a high bandwidth, compared to the microstrip line feed with a conventional microstrip antenna, as shown in Table 2. 


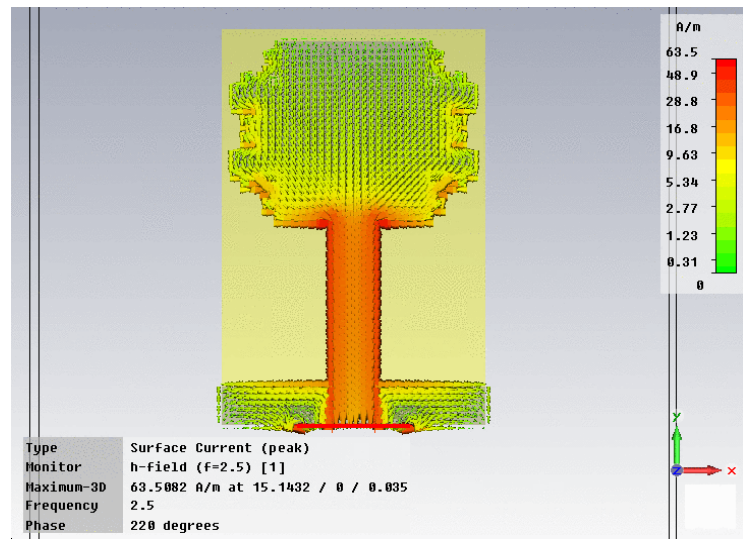

Figure 6. Surface current distributions of the proposed antenna
Table 2. Antennas Results

\begin{tabular}{cccc}
\hline At 2.45 GHz & $\begin{array}{c}\text { S11 } \\
(\mathrm{dB})\end{array}$ & $\begin{array}{c}\text { Bandwidth } \\
(\mathrm{MHz})\end{array}$ & $\begin{array}{c}\text { Gain } \\
(\mathrm{dB})\end{array}$ \\
\hline $\begin{array}{c}\text { Ordinary Patch with } \\
\text { microstrip fed }\end{array}$ & -43.5 & 60 & 1.76 \\
\begin{tabular}{c} 
Proposed Patch \\
\hline
\end{tabular} & -35.9 & 327 & 2.2 \\
\hline
\end{tabular}

\subsection{Experimental Results}

A prototype of the proposed antenna has been realized as shown in Figure 7.

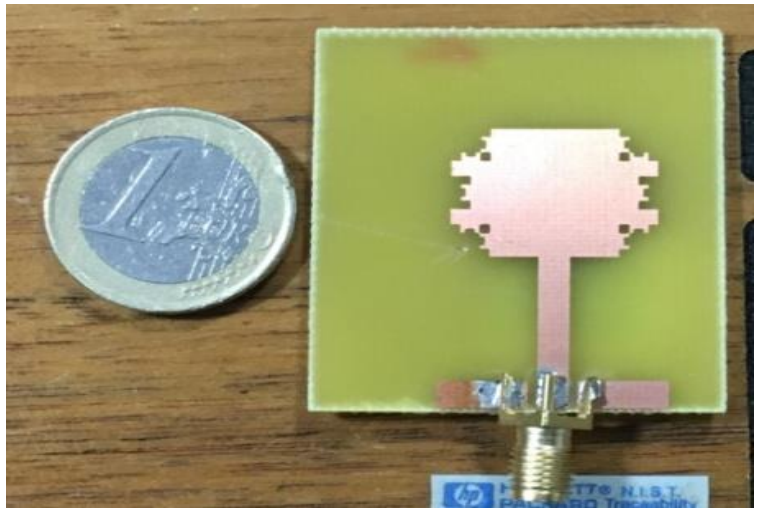

Figure 7. The antenna prototype achieved

Figure 8 compares the simulated and measured return loss of the antenna. The results, summarized in Table 3, show good agreement with a return loss of approximately $-21 \mathrm{~dB}$ at frequency $2.45 \mathrm{GHz}$.

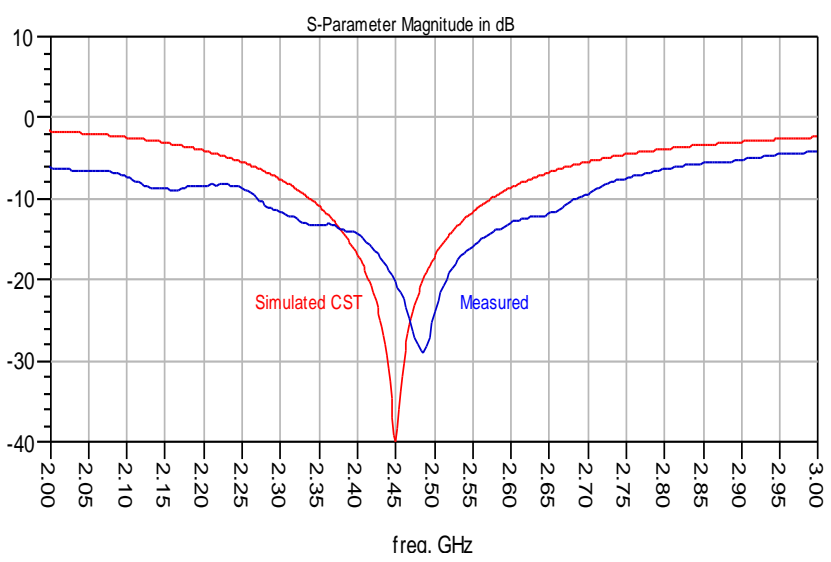

Figure 8. Measured (Blue) and simulated (Red) return loss of the proposed antenna
Table 3. Resume of Simulated and Measured

\begin{tabular}{lll} 
& \multicolumn{2}{c}{ Results } \\
\hline & S11 (dB) & Bandwidth $(\mathrm{MHz})$ \\
\hline Simulated & -35.9 & 327 \\
Measured & -21.0 & 400 \\
\hline
\end{tabular}


The proposed antenna has an omni-directional radiation pattern measured for H-plane and E-plane, as shown in Figure 9 and Figure 10.

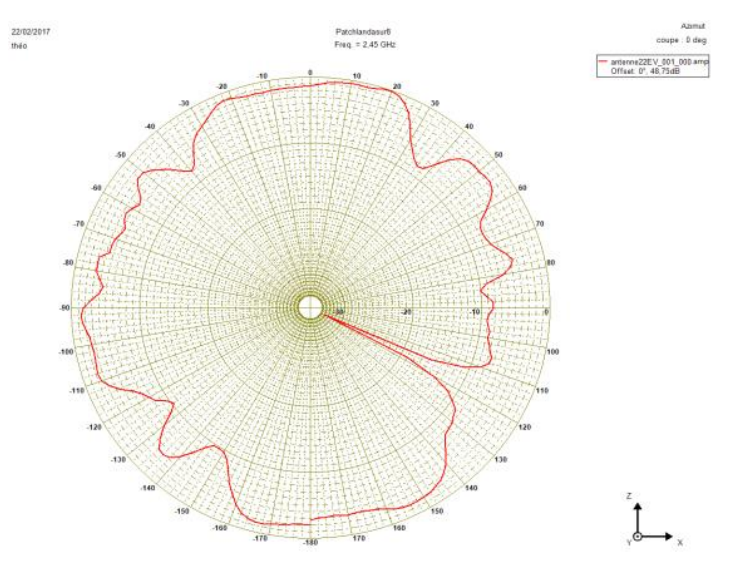

Figure 9. 2D radiation patterns measured in E-plane

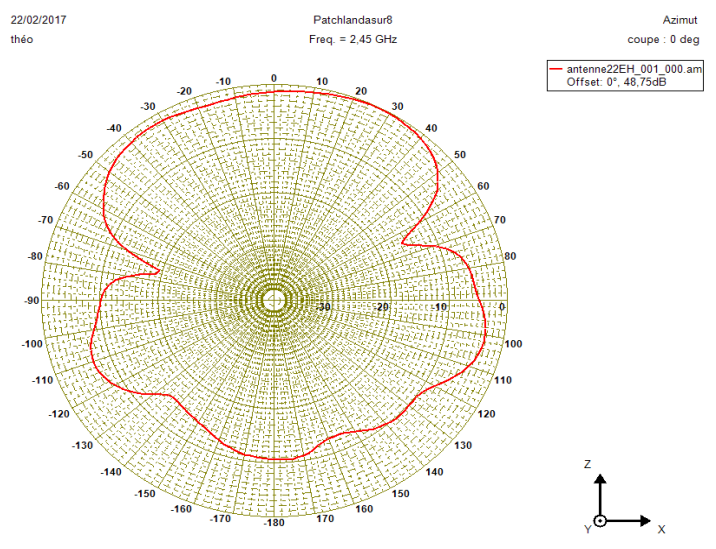

Figure 10. 2D radiation patterns measured in H-plane

As illustrated in Table 4, The total size reduction obtained, compared to some antennas operate at the same frequency of $2.45 \mathrm{GHz}$, is for example equal to $61.4 \%$ for the conventional rectangular patch antenna, $48.5 \%$ for the compact inverted Y slot rectangular microstrip patch antenna [11], 47.5\% in the case of the dual band metamaterial printed antenna based on CSRR [15], 41.5\% in the case of the compact CPWFed dual-band printed antenna [12], 41.2\% compared to the miniature planar microstrip antenna using DGS [14], and 34.6\% for the new compact CPW-Fed dual-band monopole antenna [13].

Table 4. Total Size Results

\begin{tabular}{lccc}
\hline & $\begin{array}{c}\text { Wsub } \\
(\mathrm{mm})\end{array}$ & $\begin{array}{c}\text { Lsub } \\
(\mathrm{mm})\end{array}$ & $\begin{array}{c}\text { Total size reduction } \\
\text { (Wsub x Lsub) }\end{array}$ \\
\hline Proposed patch & 32.05 & 21.22 & $\mathbf{6 1 . 4} \%$ \\
Ordinary patch with microstrip fed & 39 & 45.2 & $\mathbf{4 8 . 5} \%$ \\
Compact inverted Y slot rectangular microstrip patch antenna [11] & 40 & 33 & $\mathbf{4 7 . 5 \%}$ \\
Dual band metamaterial printed antenna [15] & 36 & 36 & $\mathbf{4 1 . 5} \%$ \\
Compact CPW-Fed dual-band printed antenna [12] & 30.6 & 38 & $\mathbf{4 1 . 2} \%$ \\
Miniature planar microstrip antenna using DGS [14] & 34 & 34 & $\mathbf{3 4 . 6} \%$ \\
New compact CPW-fed dual-band monopole antenna [13] & 30.6 & 34 & \\
\hline
\end{tabular}

\section{CONCLUSION}

This paper presents a new miniature antenna with fractal structure and CPW fed. The antenna size reduction obtained is equal to $61.4 \%$ compared to conventional rectangular patch. It provides appropriate characteristics, with a return loss equal to $-21 \mathrm{~dB}$, a bandwidth of $400 \mathrm{MHz}$, a directivity of $1.91 \mathrm{~dB}$, and a gain equal to $2.2 \mathrm{dBi}$. The antenna has been designed on a standard FR4 substrate and realized with conventional Printed Circuit Board (PCB) techniques. This antenna can be used in logistics management.

\section{ACKNOWLEDGEMENTS}

We thank Mr. Mohamed Latrach Professor in ESEO, engineering institute in Angers, France, for allowing us to use all the equipment and EM solvers available in his laboratory.

\section{REFERENCES}

[1] Nasimuddin. InTech Janeza. Microstrip Antennas. Trdine 9. Rijeka. Croatia. 2011.

[2] Guha D, Yahia M.M. John Wiley \& Sons Ltd. Microstrip and Printed Antennas: New Trends, Techniques and Applications. Antar. 2011.

[3] Ghiotto A. Tag UHF RFID Antenna Design, Application by Jet of Material. PhD Thesis. Institut Polytechnique Grenoble France; 2008. 
[4] Reynolds N. Long Range Ultra-High Frequency (UHF) Radio Frequency Identification (RFID) Antenna Design. PhD Thesis. Faculty of Purdue University Fort Wayne, Indiana; 2012.

[5] Fang D.G. Taylor and Francis Group. Antenna Theory and Microstrip Antennas. 2010.

[6] Pigeon M. Design of Ultra-Compact Antennas Based on Metamaterials, Application To The Fabrication Of A Miniature GNSS Antenna. PhD Thesis. Institut National Polytechnique Toulouse France; 2011.

[7] Nithisopa K, Nakasuwan J, Songthanapitak N, Anantrasirichai N, Wakabayashi T. Design CPW Fed Slot Antenna for Wideband Applications. Piers online. 2007; 3(7).

[8] Deleruyelle T, Pannier P, Bergeret E, Bourdel S. Dual Band UHF and Microwave RFID Antenna. Proceedings of the 38th European microwave conference. 2008.

[9] Finkenzeller K. Giesecke \& Devrient GmbH. RFID Handbook Fundamentals and Applications in Contactless Smart Cards, Radio Frequency Identification and Near-Field Communication. Third edition. Munich. Germany. 2010.

[10] Thamji M, Abdelmounim E, Bennis H, Hefnawi M, Latrach M. A Miniature L-slot Microstrip Printed Antenna for RFID. TELKOMNIKA Journal. 2018; 16(5): 1923-1930.

[11] Verma R K, Srivastava D K. A Compact Inverted Y Slot Rectangular Microstrip Patch Antenna for Bluetooth Applications. Indonesian Journal of Electrical Engineering and Computer Science. 2018; 11(2).

[12] El Hamraoui A, Abdelmounim E, Zbitou J, Bennis H, Latrach M. A New Design of a Compact CPW-Fed DualBand Printed Antenna for RFID Applications. IEEE Conference Publications, Wireless Networks and Mobile Communications (WINCOM). 2015.

[13] El Hamraoui A, Abdelmounim E, Zbitou J, Errkik A, H. Bennis H, Latrach M. A New Compact CPW-Fed DualBand Monopole Antenna for RFID Applications. Indonesian Journal of Electrical Engineering and Computer Science. 2017; 8(1).

[14] Er-rebyiy R, Zbitou J, Latrach M, Tajmouati A, Errkik A, EL Abdellaoui L. New Miniature Planar Microstrip Antenna Using DGS for ISM applications. TELKOMNIKA Journal. 2017; 15(3).

[15] Ennajih A, Zbitou J, Latrach M, Errkik A, El Abdellaoui L, Tajmouati. A Dual Band Metamaterial Printed Antenna Based on CSRR for RFID Applications. International Journal of Microwave and Optical Technology. 2017; 12(2).

[16] Borja C, Romeu J. On the Behavior of Koch Island Fractal Boundary Microstrip Antenna. IEEE Transactions on Antennas and Propagation. 2003; 51: 1281-1291.

[17] Reha A, Elamri A. Fractal Antennas: A Novel Miniaturization Technique for Wireless Networks. Transactions on networks and communications. Society for science and education United Kingdom. 2014; 2(5): 166.

[18] Monti G, Catarinucci L, Tarricone L. Compact Microstrip Antenna for RFID Applications. Progress In Electromagnetics Research Letters. 2009; 8: 191-199.

[19] Irfan N, Yagoub M, Hettak K. Design of a Microstrip-Line-Fed Inset Patch Antenna for RFID Applications. IACSIT International Journal of Engineering and Technology. 2012; 4(5).

[20] Anscy S. Slot Microstrip Antenna for 2.4GHz RFID Reader Application. International Journal of Advanced Research in Electronics and Communication Engineering (IJARECE). 2013; 2(5).

[21] Ihamji M, Abdelmounim E, Zbitou J, Bennis H, Latrach M. Novel Design of a Miniature L-Slot Microstrip CPWfed Antenna for RFID Reader. IEEE Conference Publications: The 11th International Conference on Intelligent Systems: Theories and Applications (SITA). 2016.

[22] Ferchichi A, Gharsallah A. A Novel Small Sierpenski Antenna. International Journal of Electrical and Computer Engineering (IJECE). 2013; 3(4).

[23] Guesmi C, Ferchichi A, Gharsallah A. A Modified Fractal Bow Tie Antenna for an RFID Reader. International Journal of Electrical and Computer Engineering (IJECE). 2014; 4(3).

[24] Balanis A. John Wiley \& Sons Inc. Antenna Theory Analysis and Design. 2nd edition. 2003.

[25] Ihamji M, Abdelmounim E, Zbitou J, Bennis H, Latrach M. Novel Design of a Miniature Fractal Microstrip CPW Fed Antenna for RFID Reader. IEEE Conference Publications: The International Conference on Wireless Networks and Mobile Communications (WINCOM). 2016.

[26] Thamji M, Abdelmounim E, Bennis H, Hefnawi M, Latrach M. Design of Compact Tri-Band Fractal Antenna for RFID Readers. International Journal of Electrical and Computer Engineering (IJECE). 2017; 7(1).

[27] A. Reha, A. El Amri, O. Benhmammouch, A. Oulad Said, A. El Ouadih, and M. Bouchouirbat. CPW-fed H-tree fractal antenna for WLAN, WIMAX, RFID, C-band, HiperLAN, and UWB applications. International Journal of Microwave and Wireless Technology. 2015: 1-8. 